\title{
Traumatic epithelial ingrowth despite non-displaced Lasik flap
}

\begin{abstract}
A 50-year-old female developed significant aggressive epithelial ingrowth after a minor corneal abrasion to her left eye, which required surgical removal. On presentation, she exhibited no signs of corneal flap manipulation or displacement. This report exemplifies the latest presentation of traumatic epithelial ingrowth from initial LASIK surgery and the only case without flap displacement, emphasizing the need for close follow-up and examination of all LASIK patients even after minor trauma.
\end{abstract}

Keywords: LASIK, epithelial ingrowth, laser assisted in-situ keratomileusis
Volume 3 Issue 3 - 2015

\author{
Hassan Aboumerhi, ${ }^{1,3}$ Chad Shultz, ${ }^{2}$ Erzurum \\ $S A^{1,2,3}$ \\ 'Northeast Ohio Medical University, USA \\ ${ }^{2}$ Eye Care Associates Inc, USA \\ ${ }^{3}$ St. Elizabeth Health Center, USA
}

\begin{abstract}
Correspondence: Hassan Aboumerhi, St. Elizabeth Health Center, 1044 Belmont Ave, Youngstown, OH 44504, USA, Tel
\end{abstract} 4402927602,Email haboumerhi@neomed.edu

Received: October 29, 2015 | Published: December 07, 2015
Abbreviations: LASIK, laser assisted in-situ keratomileusis; UCVA, uncorrected visual acuity; DLK, diffuse lamellar keratitis; OCT, optical coherence tomography

\section{Introduction}

Most patients undergoing laser in situ keratomileusis (LASIK) recover without issue. In certain cases, however, postoperative complications may threaten vision unless treated properly. One of these complications, corneal epithelial in growth, often occurs in the first day of $1-2 \%$ of LASIK cases. ${ }^{1}$ Epithelial cell growth may encroach on the visual axis, impairing vision. These patients may develop corneal melt leading to permanent vision loss if not treated appropriately. ${ }^{2}$ The formation of a corneal flap by LASIK leaves a potential space between the flap and the stroma. Etiologies for epithelial ingrowth are twofold: (1) cellular replication after introduction to the interface of the flap from the corneal periphery via cutting, lifting, or flap manipulation and (2) cellular migration from the flap border after surgery. ${ }^{3}$ Risk factors for epithelial ingrowth include multiple LASIK procedures and hyperopic correction as opposed to myopic correction. ${ }^{4}$ Case reports of traumatic incidents that have disrupted the corneal flap have also been reported, inducing epithelial ingrowth and, in one case, ingrowth was delayed 14years after initial LASIK. ${ }^{5}$ There are no reports of epithelial ingrowth after LASIK without corneal flap displacement. We report a case of epithelial ingrowth after minor corneal abrasion without manipulation or displacement of the LASIK flap 15 years after surgery.

\section{Case background}

A 76year old man was admitted due to upper gastrointestinal bleeding. He was hemodynamically stable. Physical examination was unremarkable except for melena on rectal examination. Nasogastric tube showed clear gastric content. There was no history of recent abdominal pain, weight lost or vomiting. On admission hemoglobin level was $8.9 \mathrm{~g} / \mathrm{dl}$. All other blood tests including coagulation profile were normal. After initial resuscitation, he underwent urgent Gastroscopy in which a sub mucosal $3 \mathrm{~cm}$ ulcerated mass was identified at the greater curvature without evidence of active bleeding. Bleeding ceased spontaneously. Further evaluation was performed. Endoscopic ultra sound showed a $3 \mathrm{~cm}$ mixed echogenicity mass arising from the sub mucosa without lymphadenopathy. Biopsies were not taken. An abdominal computer tomography confirmed the diagnosis of a $3 \mathrm{~cm}$ sub mucosal lesion with peripheral enhancement after injection of contrast material. PET CT showed a pathological uptake of FDG in the gastric tumor only (Figure 1) and a preoperative diagnosis of GIST were made.

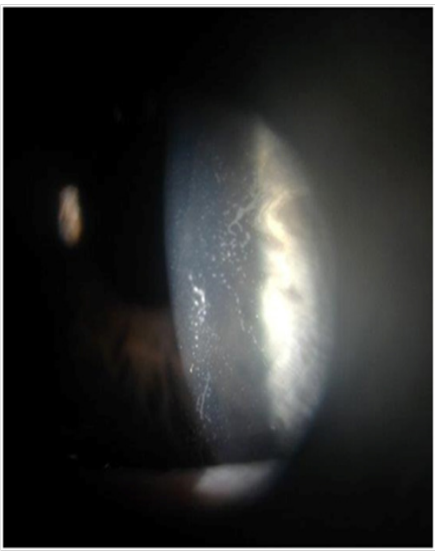

Figure I Slit lamp photograph of left cornea demonstrating epithelial ingrowth under the midperiphery of the LASIK flap with direct extension into the visual axis.

Under general anesthesia a laparoscopic exploration was performed. A $3 \mathrm{~cm}$ tumor was found at the posterior wall of the stomach (Figure 2). There were no other pathological findings during the exploration of the abdomen cavity. A wedge resection of the tumor was performed using laparoscopic staplers. The patient had uneventful recovering period and was discharged 5 days after surgery. On slides taken from lesion showed the round cells with small uniform nuclei, without nuclear pleomorphic and no mitotic figures. The distribution of round glomus cells around the open vascular lumen is a key to the pathology diagnosis. The lesion was positive for alpha-smooth muscle Actine (alpha SMA), Calponin and negative for CD-34, C-KIT and CK MNF116. The proliferating marker showed very low mitotic rate, less than one per $50 \mathrm{HPF}$. The histological examination and immunohistochemical stains confirmed diagnosis of gastric glomus tumor (Figure 3). The surgical resection margins were free of tumor. 


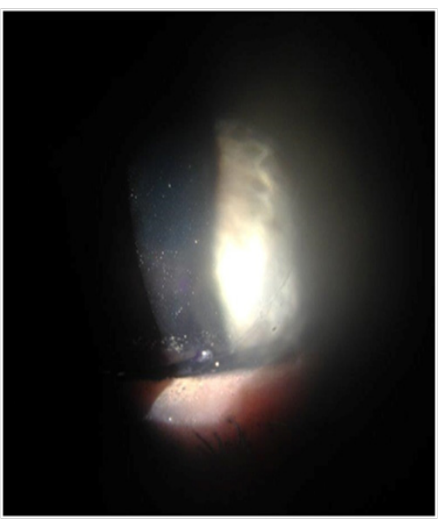

Figure 2 Slit lamp photograph of left cornea after surgical debridement of epithelial ingrowth and subsequent flap replacement.

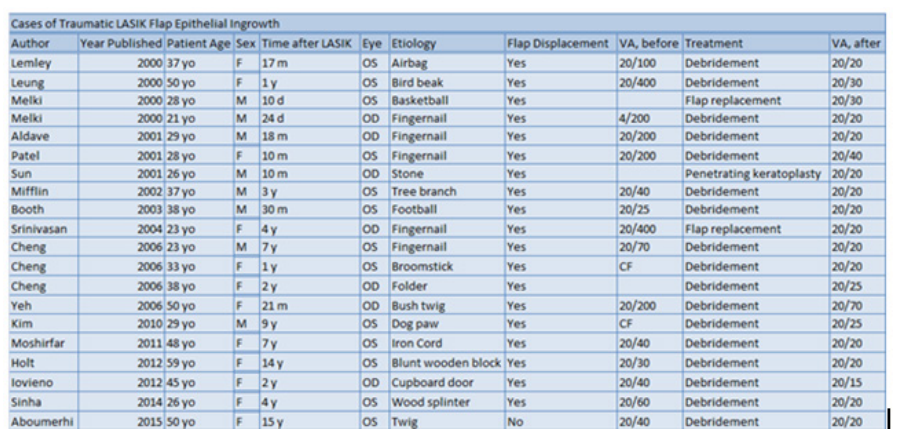

Figure 3 Cases of Traumatic LASIK Flap Epithelial Ingrowth. This case study is the latest-onset from initial LASIK and the only case without flap displacement.

\section{Discussion}

LASIK permanently changes the inherent anatomy of the cornea Once a patient undergoes LASIK surgery, the cornea heals exclusively at the periphery of the microkeratome wound away from the visual axis, thereby leaving a persistent potential space under the flap. Even years after LASIK, only minimal adhesions may hold the flap to the stroma, leaving the rest of the interface patent and predisposing the flap to displacement after trauma. ${ }^{6}$ Figure 3 describes reported cases of traumatic LASIK flap epithelial ingrowth. Mean patient age was 36 and the female to male ratio was 1:0.67. Five cases in the series were caused by finger sticks to the eye and three were from a twig or branch. Seventy percent experienced full recovery of their vision; thirty percent of patients' visual deficits remained, despite improvement. Two cases did not require debridement of epithelial ingrowth; one case in the series involving corneal perforation mandated penetrating keratoplasty. Our case is the latest-onset of traumatic epithelial ingrowth, 15years after initial LASIK, and the only case without flap displacement. $^{5-21}$

In the current case, epithelial ingrowth resolved on slit lamp exam after flap lift, debridement, and drop treatment; visual symptoms did not return. How the epithelial cells were introduced under the corneal flap remains unclear. Traumatic crystalline foreign bodies at the LASIK flap interface without flap displacement has been reported. Choi postulated that a sharp, high velocity, but weak ocular trauma could open the potential stromal space and leave debris without displacing the flap. ${ }^{20}$ We speculate a similar mechanism occurred with this patient or that the twig may have microscopically penetrated to the interface, implanting surface epithelial cells into the potential space. Cellular proliferation may have given the patient their presenting symptoms. Although corneal slit lamp examination is the standard for detecting epithelial ingrowth, anterior segment optical coherence tomography (OCT) may be a useful diagnostic tool. OCT may evaluate corneal structure changes related to disease before surgical debridement. ${ }^{21}$ After treatment, careful monitoring with close followup in these patients is necessary. Higher rates of recurrence even after surgical debridement have been reported. ${ }^{22}$

Post-traumatic epithelial ingrowth introduces cells into the corneal flap interface and corneal disturbance is observed. In this report, however, epithelial ingrowth occurred beneath the flap without any sign of disruption. This report exemplifies the need for close followup and examination of all LASIK patients even after minor trauma, since corneal anatomy is indefinitely altered. Ophthalmologists should educate patients on epithelial ingrowth as a post-operative complication and carefully monitor patients for signs, regardless of observed flap disruption or distant chronology from the initial LASIK procedure.

\section{Acknowledgements}

This original research is not under consideration elsewhere; authors have no financial disclosures or conflict of interest. All authors have made contributions to this paper for authorship, including design and conduct of the study; collection, management, analysis, and interpretation of the data; and preparation, review, or approval of the manuscript. Authors have had full access to all of the data in the study and take responsibility for the integrity of the data and the accuracy of the data analysis.

\section{Conflict of interest}

The author declares no conflict of interest.

\section{References}

1. Gimbel HV, Penno EE, van Westenbrugge JA, et al. Incidence and management of intraoperative and early postoperative complications in 1000 consecutive laser in situ keratomileusis cases. Ophthalmology. 1998;105(10):1839-1847.

2. Castillo A, Diaz-Valle D, Gutierrez AR, et al. Peripheral melt of flap after laser in situ keratomileusis. J Refract Surg. 1998;14(1):61-63.

3. Nicolas M, Abouzeid H, Deprez M, et al. Epithelial ingrowth cells after LASIK/ALTK (automated lamellar therapeutic keratoplasty):are they corneal epithelial stem cells? Br J Ophthalmol. 2012;96(7):1043-1046.

4. Mohamed TA, Hoffman RS, Fine IH, et al. Post-laser assisted in situ keratomileusis epithelial ingrowth and its relation to pretreatment refractive error. Cornea. 2011;30(5):550-552.

5. Holt DG, Sikder S, Mifflin MD. Surgical management of traumatic LASIK flap dislocation with macrostriae and epithelial ingrowth 14 years postoperatively. J Cataract \& Refractive Surg. 2012;38(2):357361.

6. Sinha R, Shekhar H, Tinwala S, et al. Late post-traumatic flap dislocation and macrostriae after laser in situ keratomileusis. Oman J Ophthalmol. 2014;7(1):25-27.

7. Lemley HL, Chodosh J, Wolf TC, et al. Partial dislocation of laser in situ keratomileusis flap by air bag injury. J Refract Surg. 2000;16(3):373374.

8. Leung ATS, Rao SK, Lam DSC. Traumatic partial unfolding of laser in situ keratomileusis flap with severe epithelial ingrowth. $J$ Cataract Refract Surg. 2000;26(1):135-139. 
9. Melki SA, Talamo JH, Demetriades A, et al. Late traumatic dislocation of laser in situ keratomileusis corneal flaps. Ophthalmology. 2000;107(12):2136-2139.

10. Aldave AJ, Hollander DA, Abbott RL. Late-onset traumatic flap dislocation and diffuse lamellar inflammation after laser in situ keratomileusis. Cornea. 2002;21(6):604-607.

11. Patel CK, Hanson R, McDonald B, et al. Late dislocation of a LASIK flap caused by a fingernail. Arch Ophthalmol. 2001;119(3):447-449.

12. Sun CC, Chang SW, Tsai RRF. Traumatic corneal perforation with epithelial ingrowth after laser in situ keratomileusis. Arch Ophthalmol. 2001;119(6):907-909.

13. Mifflin M, Kim M. Laser In Situ Keratomileusis flap dehiscence 3 years postoperatively. J Cataract Refractive Surg. 2002;28:733-735.

14. Booth MA, Koch DD. Late laser in situ keratomileusis flap dislocation caused by a thrown football. J Cataract Refractive Surg. 2003;29(10):2032-2033.

15. Srinivasan M, Prasad S, Prajna NV. Late dislocation of LASIK flap following fingernail injury. Indian J Ophthalmology. 2004;52(4):327-328.

16. Cheng AC, Rao SK, Leung GYS, et al. Late Traumatic Flap Dislocations after LASIK. J Refractive Surg. 2006;22(5):500-504.
17. Yeh DL, Bushley DM, Kim T. Treatment of traumatic LASIK flap dislocation and epithelial Ingrwth with fibrin glue. Am J Ophthalmol. 2006;141(5):960-962.

18. Kim HJ, Silverman CM. Traumatic dislocation of LASIK flaps 4 and 9 years after Surgery. J Refract Surg. 2010;26(6):447-452.

19. Moshirfar M, Anderson E, Taylor N, et al. Management of a traumatic flap dislocation seven years after LASIK. Case Reports in Ophthalmological Medicine. 2011;2011:514780.

20. Choi JA, Kim M. LASIK Interface-captured foreign bodies after mild traumatic corneal scratch without flap displacement. Korean J Ophthalmol. 2012;26(3):222-225.

21. Iovieno A, Sharma DP, Wilkins MR. OCT visualization of corneal structural changes in traumatic dislocation of LASIK flap. International Ophthalmology. 2012;32(5):459-460.

22. Henry CR, Canto AP, Galor A, et al. Epithelial ingrowth after LASIK clinical characteristics, risk factors, and visual outcomes in patients requiring flap lift. Journal of Refractive Surgery. 2012;28(7):488-492. 